\title{
$\bullet$ MISCELANEA $\bullet$
}

\section{FORO DE ENFERMERÍA PARA EL DESARROLLO}

En Alicante, un grupo de estudiantes y profesionales de la enfermería se han constituido en asociación, dándose el nombre de Foro de Enfermería para el Desarrollo, con el firme propósito de utilizar el ejercicio y la investigación enfermeras para conseguir un mayor equilibrio social, partiendo desde el respeto a las personas y su cultura. En este camino, el Foro ya ha iniciado dos proyectos de Educación para la Salud, uno destinado a niños huerfanos en Lurín (Perú), y el segundo, en su primera fases consiste en el estudio de la cultura Napuruna (Amazonia peruana), para la posterior elaboración y realización del programa educativo. Para conseguir cualquier información escriba a:

\section{David Molero Tolino}

Avda. País Valencià, n³4-portal 3 piso 3 puerta 4

\section{La Vila Joiosa}

Alicante 


\section{CONGRESO NACIONAL}

\section{DE HISTORIA}

DE LA ENFERMERÍA

- MERIDA 9, 10 Y 11 DE OCTUBRE •

\section{E.U. DE ENFERMERÍA DE MÉRIDA}

Carretera de Valverde s/n. 06800 MÉRIDA (Badajoz) Telf.: 924-33 0742 • Fax 924-33 0742 